\title{
POTENTIAL OF ELECTRICITY PRODUCTION FROM SUGARCANE RESIDUES
}

\author{
Arnaldo Walter
}

\section{INTRODUCTION}

Worldwide, sugarcane mills use their process biomass residues (mainly sugarcane bagasse) as fuel in cogeneration systems. In Brazil, during the harvest period the mills are electrically selfsufficient, that means that all electricity required is produced on-site from the bagasse. Since the second half of the 1980s, some mills (following a slow but consistent process) have done investments aiming at the production of surplus electricity to be sold to the grid. It is estimated that about $20 \%$ of the Brazilian mills, most of them located in state of São Paulo, are producing and selling surplus electricity.

However, the capacity of electricity production is significantly low regarding the potential taking into account the sugarcane production. According to the Brazilian Electricity Agency - Aneel ${ }^{1}$ - the installed capacity of electricity production from sugarcane bagasse by middle 2008 was 3.1 GW in 248 industrial units (mills). Considering that at that time there was at least 350 mills under operation, the installed capacity was more than 3.5 GW (supposing the non declared capacity in small mills), or at least 3.5\% of total existing capacity of electricity production.

The potential of electricity production depends on various factors, including the technol-

\footnotetext{
1 Agência Nacional de Energia Elétrica, in Portuguese, that is the regulatory body of the electric sector. Its data basis is available at: <www.aneel.gov.br $>$.
}

ogy of the cogeneration system (e.g., pressure and temperature of the steam raised, the use of backpressure steam turbines or extractioncondensation units etc.), the availability of biomass (e.g., the potential will be higher in case of sugarcane trash use), and on the number of hours of operation (e.g., only during the harvest season, or along the whole year). For instance, considering that steam is raised at $82 \mathrm{bar}, 480{ }^{\circ} \mathrm{C}^{2}$, without reduction of the steam demand, without the use of sugarcane trash and electricity production just during the harvest period, the potential would be equal to $6 \mathrm{GW}$ considering the sugarcane production in 2006 (425 Mt of sugarcane). On the other hand, considering the same steam parameters, but recovering $40 \%$ of the trash available at the field and reducing the steam demand, the potential would reach $9 \mathrm{GW}$ (again supposing the operation only during the harvest period). Thus, it can be concluded that the potential is at least 2 to 3 times the installed capacity.

Conversely, considering that sugarcane production can reach 730 Mt by 2012 and even surpass 1,000 Mt in 2017, the potential of electricity production from sugarcane bagasse could be more 2 to 3 times higher comparing to the previous evaluation. It is clear that these are very expressive figures taking into account the required necessity of enlargement of the electric system in Brazil in the following 10 to 20 years.

\footnotetext{
2 That no longer is the best technology commercially available in Brazil.
} 
Since many years it has been recognized many advantages of the cogeneration using residues of sugarcane, including:

(i) that it is possible to produce a reasonable amount of surplus electricity without the use of extra fuels, as the residual biomass of sugarcane has been burned anyway (the bagasse in the mills site, and the trash in the field, before harvesting) ${ }^{3}$. As the residues of sugarcane are renewable, the reduction of greenhouse gas - GHG - emissions is an additional benefit of this option. The reduction of GHG emissions depend on the sources of electricity production that are displaced due to the production from sugarcane residues;

(ii) the so called distributed electricity generation, close to the load centers, could allow the reduction of transmission and distribution losses;

(iii) in case of Brazil, the production of electricity from sugarcane residues can contribute to the electric system, as sugarcane production in the Center-South region ${ }^{5}$ occurs during the dry period, when the hydro power plants cannot operate at their full capacity;

(iv) the technology is commercially available, the required equipments are produced in Brazil and the specific investment $(\$ / \mathrm{kW}$ installed) is relatively low;

(v) the production diversification in the sugarcane industry would allow could cost reduction, modernization (both considering technological and managerial point of views) and would be a step further on making real the biorefinery concept;

\footnotetext{
3 The so-called trash corresponds to the leaves and tops of the plant that have been traditionally burned at the field before the manual harvesting process. In some regions - e.g., in state of São Paulo -, it will be completely forbidden to burn sugarcane previous to harvest in few years, and mechanical harvesting will be dominant technology.

4 These benefits are larger if the bulk of electricity production is based on fossil fuels, such as coal, oil products and natural gas.

5 Where about $90 \%$ of the sugarcane production takes place
}

(vi) and, finally, taking into account the enlargement of sugarcane production, the cogeneration potential would significantly enlarge the electricity supply within the regions Central and Northeast.

However, despite the advantages presented above, there are still considerable constraints for the deployment of the cogeneration potential, including the following aspects:

(i) there is still a hydroelectricity culture in the Brazilian electric sector and the deployment of the remaining hydro potential is the priority;

(ii) the sugarcane sector is heterogeneous and many entrepreneurs still don't recognize the advantages of producing surplus electricity. It should also be mentioned that the required investments for surplus electricity production are meaningful vis-à-vis the investments in the core business, and this is an important reason for the lack of motivation;

(iii) regarding the topic above, as the investments for surplus electricity production are not the priority, the required discount rate is larger, with a negative impact over the production costs;

(iv) the enlargement of electricity production capacity is related with window opportunities that appear when a new mill is build or when the main equipment are changed in an existing mill. In case of inadequate conditions at the moment of the decision process, the potential will be lost for about 25 to 30 years (i.e., the useful life of boilers and steam turbines);

(v) in Brazil, the regulation regarding cogeneration has remained incomplete despite the set of actions taken along the years.

In recent years (and currently), there is a new set of factors that would negatively impact the investment opportunity for large-scale production of surplus electricity using residues of sugarcane. They are:

(i) some mills/distilleries have been built in regions where there are constraints for 
interconnecting with the electric grid ${ }^{6}$. In case of high costs for selling surplus electricity, entrepreneurs decide to reduce the capacity just assuring self-sufficiency ${ }^{7}$;

(ii) currently electricity is commercialized through public auctions and this has brought new difficulties for cogeneration from biomass. First, because the process is complex in a certain extent and this imposes a constraint for those who are not familiar with the electric sector. Second, as previously mentioned, because of the few window opportunities for the required investment;

(iii) in addition, in some cases constrains regarding the supply of equipment or the necessity of reducing the up-front costs resulted investments just for self-sufficiency.

Aiming at identify the opportunities for the enlargement of electricity production form sugarcane residues, the existing challenges and the required actions mainly regarding research and development - R\&D, a workshop was held at University of Campinas - Unicamp, in January 2008. The second part of this chapter is a summary of the main discussions and conclusions of this event.

The workshop "Potential of electricity production from residues of sugarcane: opportunities, challenges and required actions" was divided in three panels. The first section had focus on the potential itself and on how this potential has been considered in the electric sector planning. The main presentation in this section was by Vicente Correa Neto, from Empresa de Pesquisa Energética $-\mathrm{EPE}^{8}$. The panel had also two opponents: Leonardo Santos Caio Filho, from COGEN-SP, and Celso Zanatto, from Crystalsev.

The second panel had focus on the required R\&D actions aiming at deploying the estimated

\footnotetext{
${ }^{6}$ Essentially, large distance to the grid and/or low connecting capacity regarding the capacity of surplus electricity production.

7 In Brazil, the costs of interconnection in case of distributed generation are due to the investor in electricity production.

8 EPE, with headquarters in Rio de Janeiro, belongs to the Ministry of Mines and Energy and is charge of all main steps regarding energy planning in Brazil.
}

maximum potential ${ }^{9}$. Three experts on technology have discussed the main issues.

Finally, the third panel was devoted to the capacity of the Brazilian industry of equipment. The presentation was by Vadson Bastos, from Dedini, and the discussion was with all participants.

\section{OPPORTUNITIES, CHALLENGES AND REQUIRED ACTIONS}

According to $\mathrm{EPE}^{10}$, electricity self-production in 2006 was equivalent to $10,6 \%$ of the total electricity consumption, and the growth rates have been remarkable in recent years. Only in the oil and gas industry electricity self-production is more important than in the sugarcane industry; considering electricity self-production, sugarcane bagasse is the second more important energy source, behind hydro.

In a conservative basis, EPE estimates that electricity production from bagasse in 2006 was at least four times lower than it would be possible to achieve in case of the widespread use of the best technology available at that time. This estimate is based on a survey done by EPE, covering about $10 \%$ of the existing mills.

The potential regarding the enlargement of the sugarcane industry up to 2030 was evaluated by EPE in its (first) National Energy Plan. It was estimated that the sugarcane production could reach 1,120 million tonnes of sugarcane in 2030 . Even in the reference case, EPE has considered a very optimistic scenario in which by 2010 most of the mills (78\%) would be relatively new, being about 60\% installed during the period 2005 e 2010.

In opposition to that optimism regarding the investments, EPE has considered that the bulk of the cogeneration units would be systems with back-pressure steam turbines. It was taken into account that the water consumption for cogeneration systems with extraction-condensation steam turbines would be inadequate for the bulk of industrial units, mainly located in regions with

\footnotetext{
9 The so-called thermodynamic potential.

${ }^{10}$ The speaker, Vicente Correa Neto, was at that time with the Energy Resources Group, Division of Energy and Economy.
} 
constraints at certain degree regarding water availability.

Taken into account the set of hypothesis considered regarding (i) the technology used in new mills, (ii) keeping some mills without improvements $^{11}$, (iii) the use as fuel of only $20 \%$ of the sugarcane trash available at the field and (iv) the use of a share of bagasse for ethanol production through hydrolysis, the capacity of surplus electricity production in 2030 was estimated as about 6,800 MW, being 4,350 MW in mills not yet built in 2005. It should be mentioned that this is indeed a very conservative evaluation.

The efforts in order to foster the potential included a specific auction for electricity produced from biomass ${ }^{12}$, the construction of special interconnection facilities ${ }^{13}$ and advances regarding the regulation of interconnection costs.

An optimistic vision was also presented by Cogen-SP ${ }^{14}$ that at that time evaluate that would be possible to install 10,000 MW of new capacity in short to mid-term. However, the vision of potential investors was different ${ }^{15}$ due to a set of constrains, mainly regarding the interconnection costs.

According to the existing regulation, the costs of interconnection are charged to the investors. As the plants of electricity production from biomass are smaller regarding fuel oil and coal power plants, the benefits of scale-effect are not possible. Power plants fueled by fuel oil or imported coal are designed to be built where the interconnection costs are lower, and this benefit doesn't exist for the biomass units. And it is also worth to mention that the electricity of the recent approved large hydro power plants (e.g., Santo Antônio e Jirau, in the Madeira river) were not charged with the very high interconnection costs.

\footnotetext{
${ }^{11}$ Even in 2030.

12 After many delays, the auction occurred in 2008.

${ }^{13}$ Collecting facilities were designed and built aiming at reducing the costs of interconnection.

${ }_{14}$ That aims at foster cogeneration from different fuels, including biomass. The person who did the presentation was Caio Filho.

${ }^{15}$ Celso Zanatto, from Crystalsev, spoke on behalf of potential investors.
}

The required $R \& D$ actions are discussed in the following paragraphs. According to Antônio Bonomi ${ }^{16}$ there are six main technological challenges, being five of them specific to the technology and/or the biomass. The following points were highlighted:

(i) the technology BIG-GT (biomass integrated gasifier to gas turbines) - still not commercial - requires both the development of large-scale biomass gasifiers and of a clean-up technology that would allow fuel gas use in gas turbines;

(ii) it would be necessary to use multiple fuels in steam boilers, aiming at diversify the biomass supply;

(iii) the use of sugarcane trash as fuel is not possible at this moment, and all constrains regarding harvesting, transportation and storage should be addressed;

(iv) currently, the biodigestion of vinasse is not feasible, and priority should be given to the use of fuel for electricity production;

(v) the combined production of biofuels and electricity should be diversified and in the case of sugarcane it is necessary the development of hydrolysis and gasification process that would be integrate to the conventional production process.

It was also highlighted that the concept of biorefinery still needs to be developed to sugarcane.

Two other experts have discussed the required $\mathrm{R} \& \mathrm{D}$ actions for fostering cogeneration from sugarcane residues ${ }^{17}$; they agreed with the comments of the first speaker, but with some additional comments. Regarding the use of sugarcane trash as fuel, it was highlighted that it is necessary to develop technology in order to burn trash in the same conditions as bagasse has been burned. Due to its properties, problems as fouling and slagging are predicted in case of trash burning; the usual

\footnotetext{
${ }^{16}$ At that time, with the Instituto de Pesquisas Tecnológicas - IPT (Technology Research Center, in São Paulo).

${ }^{17}$ Luiz Horta Nogueira, from Unifei - Federal University of Itajubá, and Manoel Regis Lima Verde Leal, from CTBE Bioethanol Science and Technology National Laboratory.
} 
alternative of boiler derating (reducing steam pressure and temperature) would imply drastic efficiency reduction of the cogeneration system.

Concerned to gasification, Teacher Lima Verde Leal stated that it is already possible to keep on the BIG-GT demonstration project that was previously considered; this unit would use residual biomass from sugarcane and could be semi-integrated to a sugarcane mill, in order to reduce costs. According to him, both in the case of bagasse/trash gasification as well as in the case of trash burning the current required actions are regarding development and demonstration rather, than basic research; thus, the role of industries is fundamental, and specific financing programs need to be defined.

Regarding vinasse biodigestion, the most important comment was about the necessity to be careful on the evaluation, as the main issues are not related to technology development but rather to the constrained feasibility of electricity production using biogas as fuel.

The issue of the national industry capability was first addressed by the company Dedini that is the largest equipment supplier for the sugarcane industry ${ }^{18}$. A synthesis of the main topics addressed is presented below:

(i) the national industry is able to supply the required equipment aiming at producing electricity in large-scale in with higher efficiency, including steam generators able to raise steam and higher pressure and temperature (e.g., 100 bar and temperatures higher than $500{ }^{\circ} \mathrm{C}$ ). Despite critics, the industry has also positively answered to the challenges;

(ii) the national industry is able to be a partner in $R \& D$ programs, in general, and specifically in the required programs aiming at the gasification of sugarcane biomass and efficient trash burning. According to the company, the partnership with Fapesp, with an agreement signed in 2007 is a clear evidence, but in early 2008 the company was waiting for proposals;

18 The presentation was by Vadson Bastos. (iii) regarding the necessary conditions to expand the production of the main required equipment, the industry believes that the main issue is the financing conditions, which need to be set according to the necessities;

(iv) the industry states that along the years learning-effects have been observed regarding the equipment of cogeneration systems produced in Brazil ${ }^{19}$. According to the company there are specific aspects concerned to the most adequate configuration to each mill and cost's reduction could be accelerated with the growth of the market and also with technological development (that requires both private and public funds);

(v) on the other hand, the economic benefits due to standardization of equipment will barely achieved as the optimum design is different mill to mill;

(vi) finally, regarding the lack of competition in this industrial branch, the statement is that there is no market protection and that any competitor is free to enter in the market. The national industry was ever able to answer to the market demands, and along the years has produced with quality, relatively lower costs and respecting dead lines.

\section{FINAL CONSIDERATIONS}

In short-term, the main constrains for the enlargement of electricity production from sugarcane biomass are not technological neither regarding equipment supply. The main constrains are regulation and due to the lack of adequate policies, especially in short-term, because at least a reasonable part of the potential that can be developed in the existing window opportunity will be lost. The message that was presented by EPE is that the company has understood the constraints and efforts have been done to overcome most of them.

${ }^{19}$ Despite the statement of some experts who believe that learning-effects have not been observed regarding this industrial branch. 
On the other hand, in mid - to long-term the potential of electricity production - and also the potential of production of second-generation biofuels - could be jeopardize in case of no ability in burning sugarcane trash efficiently and neither gasifying bagasse/trash in large scale. In the case of ethanol production through hydrolysis, the potential will be drastically reduced if it would be impossible to raise steam at higher pressure/ temperature using trash as fuel - also with severe impacts on the potential of electricity production. In the case of biofuels production through biomass gasification, the challenge is the production of fuel gas in large scale, and also its cleaning-up.

The technology development regarding biomass hydrolysis and biomass gasification (aiming at the production of synthesis gase ${ }^{20}$ ) requires very-well defined strategies that would involve international cooperation. A reasonable number of countries have invested on such technologies and it seems that the best strategy would involve international cooperation in a certain degree; specifically regarding gasification for the production of synthesis gas, an endogenous R\&D program would be slower and with more risks. Brazil is country that calls the attention of the international investors, because the availability of low-cost biomass, the tradition regarding biomass and biofuels, and also because the knowledge available; thus, Brazil is a position to negotiate with the main technological players.

It is also worth to mention the importance of the development of biorefineries concept, that requires the knowledge regarding the biomass, the know-how of pretreatment technologies and the same regarding conversion technologies (e.g., hydrolysis, gasification and gas cleaning, among others).

Taken into account the target of enhancing electricity production from sugarcane biomass, it seems that vinasse's biodigestion should receive lower priority. However, it not wise just ignoring its potential.

${ }^{20}$ The Fischer-Tropsch conversion process is commercial, and once the drawbacks of biomass gasification and gas clean-up would be overcame, the commercial production of biofuels would be possible in large-scale. 